\title{
BREVES NOTAS SOBRE A RESPONSABILIDADE CIVIL DOS PROVEDORES DE APLICAÇÕES DE INTERNET NA PERSPECTIVA CIVIL-CONSTITUCIONAL
}

\author{
João Quinelato de Queiroz ${ }^{1}$ \\ Eduardo Nunes de Souza ${ }^{2}$
}

RESUMO: Pretende-se abordar os principais pontos polêmicos sobre o regime de responsabilidade civil do provedor de aplicações de internet por danos decorrentes de conteúdos gerados por terceiros, previsto no art. 19 do Marco Civil da Internet, a partir da perspectiva civil-constitucional. Conclui-se pela inconstitucionalidade desse regime, fundamentando-se, primordialmente, (i) inexistência de hierarquia entre o princípio da liberdade e princípio da dignidade da pessoa humana e (ii) afronta o art. $5^{\circ} \mathrm{X}$ da $\mathrm{CF} / 88$, por condicionar a reparação do dano decorrente de violações aos direitos personalíssimos ao prévio ajuizamento de demanda judicial.

Palavras-chave: Marco Civil da Internet; Dignidade da Pessoa Humana; Responsabilidade Civil.

\section{THE CIVIL LIABILITY OF THE PROVIDERS OF INTERNET APPLICATIONS IN THE CIVIL-CONSTITUTIONAL PERSPECTIVE: SHORT NOTES}

\begin{abstract}
It is intended to address the main controversial points about the civil liability regime of the Internet application provider for damages arising from contents generated by third parties, foreseen in art. 19 of the Civil Registry of the Internet, from a civil-constitutional perspective. It is concluded that this regime is unconstitutional, based primarily on (i) the absence of a hierarchy between the principle of freedom and the principle of the dignity of the human person and (ii) violation of article $5^{\circ} \mathrm{X}$ of Brazilian Constitution, for conditioning the reparation of damages resulting from violations of personal rights to the prior filing of a lawsuit
\end{abstract}

Keywords: Civil Internet Framework; Person Dignity Principle; Civil Liability.

\footnotetext{
${ }^{1}$ Mestre em Direito Civil pela Universidade do Estado do Rio de Janeiro (UERJ). Professor de Direito Civil do IBMEC e de pós-graduações em Direito. Secretário-geral da Comissão de Direito Civil da OAB-RJ. É associado ao Instituto Brasileiro de Direito Civil - IBDCivil e à Association Henri Capitant des Amis de la Culture Juridique Française. Advogado.

${ }^{2}$ Doutor e Mestre em Direito Civil pela Universidade do Estado do Rio de Janeiro (UERJ). Professor Adjunto de Direito Civil da Faculdade de Direito da Universidade do Estado do Rio de Janeiro (UERJ). Assessor jurídico junto ao Tribunal de Justiça do Estado do Rio de Janeiro (TJERJ). Conselheiro Executivo da Civilistica.com Revista Eletrônica de Direito Civil.
}

Rev. de Direito, Governança e Novas Tecnologias | e-ISSN: 2526-0049 | Porto Alegre | v. 4 | n. 2 | p. 61 - 82 | Jul/Dez. 2018 


\section{INTRODUÇÃO}

F.C.C., 38, negro, tem sua foto exibida no perfil do Facebook denominado "Bandido Bom é Bandido Morto". Ajuíza ação no Tribunal de Estado do Rio de Janeiro, requerendo a exclusão do perfil falso, já que nunca foi “bandido" e sua imagem, portanto, estaria sendo associada a um suposto criminoso. É requerido a apresentar nos autos certidão de antecedentes criminais. $\mathrm{O}$ autor fez diversas solicitações extrajudiciais ao Facebook, que não retirou o material imediatamente. Em contestação, aduziu o Facebook que o julgamento sobre o uso da imagem como legítimo ou não caberia ao poder judiciário, nos termos do art. 19 do Marco Civil. A sentença condenou o provedor ao pagamento de indenização por danos morais ao Autor, sentença está confirmada pelo Tribunal Fluminense. Em sede de Recurso Especial, o STJ acolheu recurso do Facebook, julgando a demanda improcedente, asseverando que “conclui-se pela impossibilidade de condenação do Facebook pelas ofensas geradas pelos conteúdos postados por terceiros em razão da ausência de prévia notificação judicial de retirada do material. ${ }^{3}$

J.C., 26 anos, é vítima de boato que gravemente atinge sua honra, imagem e bom nome, que circulou por grupos de Whatsapp e Facebook. Narrava o boato que a jovem teria se envolvido em relações sexuais dentro de um veículo e, durante o ato, supostamente teriam ocorridos fatos íntimos desagradáveis à vítima. O material teria circulado por 332 contas de Facebook, com 251 curtidas, 72 comentários e inúmeros grupos de Whatsapp, todos listados nos autos. ${ }^{4}$ Desde a data do ajuizamento da ação, transcorreram-se mais de 2 (dois) anos e 8 (oito) meses de duração do processo sem que o judiciário tenha dado, ainda, a última palavra sobre o caso.

Um segundo caso remonta ao famoso caso da escola Base de São Paulo, ${ }^{5}$ mas desta vez, ocorrido nas redes sociais e não na mídia impressa e televisiva. Eis o caso: J.V., tio de M.V., criança negra, publica em sua timeline que a escola onde sua sobrinha estudava, em Bauru-SP, teria feito "vista grossa" para os comentários racistas de outras crianças da escola em relação à sua sobrinha. Em um período de apenas quatro dias, a publicação em questão foi compartilhada

\footnotetext{
${ }^{3}$ STJ, $3^{\text {a }}$ T., REsp 1.642.997/RJ, Rel. Min. Nancy Andrighi, julg. 12.9.2017.

${ }^{4}$ TJPR, $11^{\text {a }}$ C.C., Ap. Civ. 0033794-69.2015.8.16.0000, Rel. Des. Sigurd Roberto Bengtsson, julg. 22.2.2017.

${ }^{5}$ A Escola Base era localizada na Cidade de São Paulo e em 1992 foi alvo de queixas de agressões e assédio sexual cometidos contra seus alunos, crianças, supostamente promovidas pelo casal dono do estabelecimento. As queixas foram publicadas em jornais de grande circulação e, inclusive, no Jornal Nacional (TV Globo). Posteriormente à divulgação dos fatos, apurou-se que eram falsos. Os donos da escola ajuizaram ação em face de veículos de mídia e receberam indenizações pelos danos sofridos. Até hoje recuperam-se dos traumas e danos materiais a que foram submetidos. (STJ, $2^{\mathrm{a}}$ T., REsp 351.779/SP, Rel. Min. Eliana Calmon, julg. 19.11.2002). Sobre o tema, vide Ribeiro (2003).
}

Rev. de Direito, Governança e Novas Tecnologias | e-ISSN: 2526-0049 | Porto Alegre | v. 4 | n. 2 | p. 61 - 82 | Jul/Dez. 2018 
mais de 825 vezes, além de receber 883 curtidas e 91 comentários por usuários do Facebook. A escola ajuíza ação com pedido de liminar requerendo a retirada do conteúdo ofensivo da página do tio da aluna, sustentando que as alegações, além de inverídicas, eram difamatórias e abalavam a credibilidade da escola perante a comunidade. Indeferida a liminar, foi julgada procedente a demanda em primeira instância, condenando o tio a indenizar o estabelecimento e a retirar o conteúdo. ${ }^{6}$ Desde a data do ajuizamento da ação, transcorreram-se 2 (dois) anos e 10 (dez) meses para que a demanda transitasse me julgado. Enquanto isto, a escola viu-se de mãos atadas em face do comentário danoso do Autor, cuja veracidade não foi comprovada nos autos pelo autor da ofensa.

De comum, entre esses casos, há mais que usuários da internet alegando violações graves à sua dignidade e reputação. Em comum, há o decurso de um longo prazo sem que a justiça tenha resolvido o problema que a ela foi apresentado, revelando a ineficácia de meios judiciais para resolver os dilemas do mundo digital. Na lição de Stefano Rodotà (2008, p. 42), "a nova angústia nasce da consciência da forte defasagem entre a rapidez do progresso técnicocientífico e a lentidão com que amadurecem a capacidade de controle dos progressos sociais que acompanham tal progresso".

Os diferentes casos comungam, também, o aparente confronto entre os direitos constitucionais à liberdade de expressão (art. $5^{\circ}$ IX da Carta da República) e a intimidade, a vida privada, a honra e a imagem dos envolvidos (art. $5^{\circ} \mathrm{X}$ da Constituição), requerendo-se do intérprete o uso do método da ponderação para solução desses casos difíceis (BARROSO, 2004, p.3).

Não é crível que em tempos de big data, armazenamento em nuvem e comunicação instantânea, um dilema da internet leve décadas para ser resolvido, ao passo que bastam alguns poucos minutos para um boato pornográfico ou uma grave ofensa se disseminarem por grupos de WhatsApp, timelines do Facebook ou Twitter. Há um descompasso entre a rapidez com que avançam as inovações tecnológicas e a lentidão com que o Direito reage a esses desafios. $\mathrm{Na}$ lição de Stefano Rodotà (2006, p. 19), “ao lado da percepção, sempre mais clara, dos riscos do progresso tecnológico, existe a consciência da impossibilidade de parar tal progresso, mesmo se este não se apresenta mais com estimativas apenas positivas”. Fica a indagação inicial: há, no Brasil, mecanismos de responsabilidade civil capazes de responder, em tempo e

\footnotetext{
${ }^{6}$ TJSP, $1^{\text {a }}$ C.D.P, Ap. Civ 1006024-23.2014.8.26.0071, Rel. Des. Christine Santini, julg. 30.8.2016.
} 
adequadamente, às violações da intimidade e vida privada dos usuários do WhatsApp, Twitter e Facebook, sem comprometer os níveis de liberdade de expressão que se esperam da internet?

Para encontrar a resposta a esses dilemas, o Estado precisa estar presente através de ações afirmativas. A intervenção Estatal, por vezes, é vista como uma ameaça à liberdade de expressão - concepção equivocada na visão de Owen M. Fiss (2005). ${ }^{7}$ Ao notar a dimensão defensiva (contra ingerências indevidas da autoridade estatal) e a dimensão protetiva (que demanda a intervenção estatal para a efetivação do seu conteúdo participativo) da liberdade, o autor demonstra a importância de pensar-se em um modelo intermediário de atuação do Estado, no qual esse é chamado a regular as liberdades para a garantia da própria liberdade. ${ }^{8}$

A recente experiência vem demonstrando que deixar com que os próprios agentes regulem o que é (e o que não é) justo e correto no mundo da internet não vem dando bons resultados, reforçando-se a importância da regulação do setor. O caso Napalm ilustra bem esse caso. Uma foto histórica, registrada em 8 de junho de 1972, tornou-se símbolo da guerra do Vietnã e foi censurada pelo Facebook por ser considerada pornografia infantil pelo provedor. Tratava-se de uma imagem que retratava a pequena menina Kim Phúc, de 9 anos de idade, nua, descalça e correndo, ao lado de outras vítimas, durante o ataque de uma bomba de Napalm, na Guerra do Vietnã. Um registro histórico de tempos sombrios, um fato indelével da história, que não se cogitaria de ser confundido com pornografia simplesmente por, na imagem, conter o triste retrato de uma criança nua e descalça. O Facebook havia banido o compartilhamento desta imagem através de mecanismos automáticos. Kim Phúc, a retratada, relatou ao The Guardian (2016) que "apoia plenamente a imagem documental tirada por Nick Ut como um momento de verdade que captura o horror da guerra e seus efeitos sobre vítimas inocentes".

Os novos tempos inauguram novos desafios não só na tecnologia, mas, também, no campo do Direito. A responsabilidade civil vem sofrendo radical mudança em sua perspectiva:

\footnotetext{
${ }^{7}$ A concepção do autor é a de que a tradicional presunção do Estado como inimigo da liberdade é enganosa, de modo que o Estado poderia se tornar o amigo ao invés do inimigo da liberdade: "Nós estamos sendo convidados, ou mesmo intimados, a reexaminar a natureza do Estado moderno e verificar se ele possui algum papel na preservação das nossas liberdades mais básicas. (...) Certamente, o Estado pode ser um opressor, mas ele pode ser também uma fonte de liberdade." (FISS, 2005, p. 28).

${ }^{8}$ Owen M. Fiss (2005), ao analisar as críticas de intervenção do Estado feitas nos Estados Unidos da América, considerando a existência da Primeira Emenda no país, defende, ao revés, que a intervenção é ferramenta de garantia do livre exercício do direito de liberdade de expressão. Diz o autor que a agência que ameaça o discurso não é o próprio Estado, já que o chamado à intervenção estatal é baseado não na teoria de que a atividade a ser regulada é intrinsecamente violadora da Primeira Emenda, mas apenas na teoria de que a promoção do debate aberto e integral, assegurando que o público ouça a todos que veria, é um fim permitido ao Estado. Mesmo se a dinâmica silenciadora é empreendida por mãos privadas, há ampla base para intervenção. O Estado estaria, portanto, segundo o Autor, exercendo seu poder de polícia para promover um fim público legítimo, como ele faz quando edita uma lei de controle de armas ou de controle de velocidade no trânsito.
}

Rev. de Direito, Governança e Novas Tecnologias | e-ISSN: 2526-0049 | Porto Alegre | v. 4 | n. 2 | p. 61 - 82 | Jul/Dez. 2018 


\section{BREVES NOTAS SOBRE A RESPONSABILIDADE CIVIL DOS PROVEDORES DE APLICAÇÕES DE INTERNET NA PERSPECTIVA CIVIL-CONSTITUCIONAL}

do ofensor à vítima (BODIN DE MORAES, 2003). A busca da reparação dos danos causados à vítima passa a ser o mote da responsabilidade civil. ${ }^{9}$ A responsabilidade civil tradicional, calcada na comprovação estática e formal dos seus requisitos - culpa, nexo e dano, chamados filtros da responsabilidade civil - cede espaço a uma dogmática menos obcecada pela verificação desses filtros, no caso concreto, e mais dedicada à eliminação desses filtros quando esses servem meramente como óbices capazes de filtrar, arbitrariamente, o que merece ou não ser acolhido pelo juridiciário. Assiste-se à chamada erosão dos filtros tradicionais da responsabilidade civil, concretizada por meio da relativa perda de importância da prova da culpa e da prova do nexo causal como obstáculos ao ressarcimento dos danos na dinâmica das ações de ressarcimento (SCHREIBER, 2015b, p. 11-12).

No mesmo caminho, verificou-se a insuficiência do critério de imputabilidade moral, com base na culpa, para a atribuição da responsabilidade pelos danos causas à dignidade, assistindo-se à transição para o modelo de mera assunção desse risco em face do causador de dano, desonerando a vítima de uma prova quase impossível, diminuindo a margem de discricionariedade judicial na exoneração do dever de indenizar e forçando o agente a internalizar o custo de sua atividade (BODIN DE MORAES, 2008, p.30-31).

Em rota de colisão com essas tendências se pôs o Marco Civil da Internet, ao instituir a responsabilidade civil subjetiva do provedor de aplicações decorrente de conteúdos gerados por terceiros, conforme seu artigo 19. Ao se deparar com os mecanismos de responsabilidade civil incidentes sobre danos ocorridos na internet, o intérprete deve estar atento aos novos contornos que este instituto vem assumindo na dogmática e orientar-se no sentido de não se apegar cegamente aos requisitos formais clássicos da responsabilidade civil e entender que, em se tratando de novos danos no contexto de uma responsabilidade civil, nexo de causalidade e culpa são menos relevantes que a finalidade principal de indenizar adequadamente as vítimas de ofensas sofridas na internet e, sobretudo, de se criar mecanismos que evitem a propagação de danos à personalidade nesses ambientes.

\footnotetext{
${ }^{9}$ Nesse sentido: "A radical mudança de perspectiva aqui apenas reflete, e não poderia ser diferente, a metamorfose dos papéis do lesante e do lesado no sistema de responsabilidade civil em geral. Se antes a vítima era obrigada a suportar, corriqueiramente, o dano sofrido - dano cuja causa, na maior parte das vezes, se atribuía não a seu autor, mas ao destino, à fatalidade, ou à vontade de Deus -, já em meados de século XX passaria ela, a vítima, a desempenhar a função protagonista da relação jurídica instaurada a partir do evento danoso, conseguindo garantir de forma cada vez mais eficaz o seu crédito, isto é, a reparação". (BODIN DE MORAES, 2003, p. 148).
} 
Ora, enquanto a erosão dos filtros ${ }^{10}$ levou a que um maior número de pretensões passasse a ser gradativamente acolhido pelo Poder Judiciário (SCHREIBER, 2018, p. 640), o Marco Civil da Internet caminhou em sentido justamente oposto. Foram impostos ao usuário novos filtros de responsabilidade civil ao provedor de aplicações - notadamente a obrigatoriedade de busca do judiciário e a indicação precisa e exata do conteúdo por meio da indicação de URL -, ignorando-se a historicidade do conceito de dano (HESPANHA, 2015), não o atualizando-o para tempos de internet e redes sociais com vista a garantir o ressarcimento da vítima e a proteção integral da dignidade da pessoa humana, como alternativa ao modelo de (quase) irreparação vigente no Marco Civil. ${ }^{11}$ Na lição de Maria Celina Bodin de Moraes (2003, p. 150), se, por um lado, a noção de risco serve a explicitar a historicidade do conceito de responsabilidade civil, "a historicidade se estende também a seu elemento ineliminável, o dano, fazendo com que se tenha que reconhecer que cada época tem seus danos indenizáveis."

O presente estudo tem como premissa metodológica a escola do direito civilconstitucional. ${ }^{12}$ Trata-se de metodologia jurídica orientada à efetivação dos princípios e valores constitucionais na ordem privada (PERLINGIERI, 2008, p.570). ${ }^{13}$ A entrada em vigor da Constituição da República de 1988 traz um novo desafio aos intérpretes do Direito Civil: garantir a tutela das situações patrimoniais e existenciais a partir da ótica da dignidade da pessoa humana, da funcionalização dos institutos, da incidência direta das normas constitucionais sobre o ordenamento privado (TEPEDINO, 2009, p. 8) e da predominância das situações existenciais sobre as patrimoniais (LOBO, 2008, p. 21). O advento da nova Carta faz com que o Código Civil de 1916, e inclusive o Código de 2002, deixem o posto de constituição do direito privado, pondo em xeque a pretensa completude dos códigos para regular a vida privada em comunidade (MONTEIRO FILHO, 2008, p. 262) . As normas de Direito Privado passam a ser

\footnotetext{
${ }^{10}$ No que tange à erosão dos filtros, tem-se que "toda essa erosão sofrida pelos pressupostos da responsabilidade civil corresponde, por um lado a uma natural ampliação da titela dos interesses jurídicos diante de uma ordem jurídica pautada pela proteção à dignidade humana e à solidariedade social, por outro lado, impõe reflexão sobre as consequências da responsabilidade civil, em especial sobre seu principal efeito, que é o deve de reparar o dano sofrido". (SCHREIBER, 2018, p. 640).

${ }^{11}$ Acerca da historicidade dos conceitos jurídicos, vide, por todos, Pietro Perlingieri (1998, passim).

${ }^{12}$ Cf TEPEDINO, Gustavo. Premissas metodológicas para a constitucionalização do Direito Civil. Temas de direito civil. Rio de Janeiro: Renovar, 2004, passim. No mesmo sentido: TEPEDINO, Gustavo. Normas constitucionais e relações de direito civil na experiência brasileira, in Temas de Direito Civil- Tomo II. Rio de Janeiro: Renovar, 2006, p. 21-46; BODIN DE MORAES, Maria Celina. A caminho de um Direito Civil Constitucional, Revista de Direito Civil, $\mathrm{n}^{\circ}$ 65, jul./set. 1993, p. 21-65; BODIN DE MORAES, Maria Celina. Constituição e Direito Civil: tendências, Revista dos Tribunais, ano 89, v. 779, set. 2000, p. 47-63.

${ }^{13} \mathrm{Na}$ definição de Pietro PERLINGIERI, o direito civil-constitucional representa uma "releitura do Código Civil e das leis especiais à luz da Constituição republicana" (PERLINGIERI, Pietro. O direito civil na legalidade constitucional. Trad. Maria Cristina De Cicco. Rio de Janeiro: Renovar, 2008, p. 570).
} 
vistas a partir de três eixos fundamentais (BODIN DE MORAES, 2016, p.56): (i) a prioridade da função dos institutos jurídicos em relação à sua estrutura); (ii) a preocupação com a historicidade e a relatividade na interpretação-aplicação do direito; e (iii) a prevalência das situações existenciais sobre as patrimoniais (ou a subordinação destas àquelas).

\section{A RESPONSABILIDADE CIVIL DOS PROVEDORES DE APLICAÇÕES POR DANOS DECORRENTES DE CONTEÚDOS GERADOS POR TERCEIROS À LUZ DO MARCO CIVIL DA INTERNET: O ITINERÁRIO JURISPRUDENCIAL DO SUPERIOR TRIBUNAL DE JUSTIÇA}

Em uma síntese entre o que a jurisprudência e doutrina defendem antes e depois da entrada em vigor do Marco Civil, pode-se dizer que a responsabilidade civil dos provedores de aplicação ${ }^{14}$ na internet segue três entendimentos distintos: (i) a não responsabilização do provedor em razão da conduta praticada pelos seus usuários, por ser o servidor mero intermediário entre usuário e vítima; (ii) a responsabilidade civil objetiva do provedor, fundada no conceito de risco de atividade ou no defeito da prestação dos serviços e (iii) a responsabilidade civil subjetiva, subdividindo-se esta corrente entre aqueles que defendem a responsabilidade civil subjetiva decorrente da inércia após ciência do conteúdo ilegal e aqueles que defendem a responsabilização somente em caso de descumprimento de ordem judicial específica - sendo esta última a teoria adotada pelo Marco Civil. ${ }^{15}$

Os defensores da primeira corrente entendem que os provedores de aplicação da internet seriam meros intermediários entre o causador do dano (o usuário da aplicação a internet) e a vítima, de modo que, nesses casos, os provedores de aplicação foram são excluídos do polo passivo por ilegitimidade passiva. ${ }^{16}$

Importante, no âmbito da aplicação desta primeira corrente, destacar a experiência dos Estados Unidos que, em decorrência do artigo 230 (c)(1) do Telecommunication Decency Act

\footnotetext{
${ }^{14}$ Por provedor de aplicação de internet, nos termos do art. $5^{\circ}$ VII do Marco Civil, entende-se: "VII -aplicações de internet: o conjunto de funcionalidades que podem ser acessadas por meio de um terminal conectado à internet". Por provedor de conteúdo, entende-se aqueles "que disponibilizam na rede os dados criados ou desenvolvidos pelos provedores de informação ou pelos próprios usuários da web". (STJ, 3 $3^{\mathrm{a}}$ T., RESP 1.316.921/RJ, Rel. Min. Nancy Andrighi, julg. 26.6.2012).

15 O próprio Superior Tribunal de Justiça, em recente julgado, já se manifestou a respeito destas correntes doutrinárias. Vide STJ, 3a T., REsp 1.642.997/RJ, rel. Min. Nancy Andrighi, julg. 12.9.2017.

${ }^{16}$ TJRS, $9^{\text {a }}$ C.C., Ap. Civ. 70061451191, Rel. Des. Miguel Ângelo da Silva, julg. 29.10.2014. Vide, ainda TJPR,

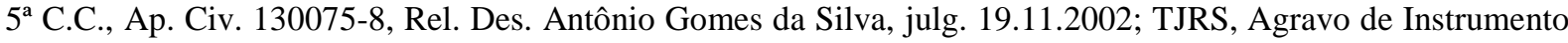
$\mathrm{n}^{\mathrm{o}}$ 7003035078, Rel. Des. Paulo Antonio Kretzmann, julg. 22.11.2001.
}

Rev. de Direito, Governança e Novas Tecnologias | e-ISSN: 2526-0049 | Porto Alegre | v. 4 | n. 2 | p. 61 - 82 | Jul/Dez. 2018 
$(\mathrm{CDA})^{17}$ confere uma isenção de responsabilidade aos provedores de serviços pelas condutas de terceiros. Esta regra comporta exceções no sistema norte-americano, como é o caso da responsabilização civil do provedor em caso de inércia na retirada de materiais que infrinjam direitos autorais. O DMCA (Digital Millenium Copyright Act), em seu artigo 512 (d), faz uma ressalva ao referido artigo 230 do CDA, responsabilizando os provedores caso não retirem do ar o conteúdo apontado extrajudicialmente como infringente de direitos autorais.

Esta primeira corrente encontra-se superada: o exame das decisões judiciais brasileiras revelava uma firme marcha rumo à superação da tese da irresponsabilidade das sociedades empresariais proprietárias de redes sociais, já que tais sociedades qualificavam-se como meras gestoras no afã de buscar sua irresponsabilidade. (SCHREIBER, 2015a)

Já a segunda corrente entende pela responsabilidade civil objetiva do provedor de serviços, com dois principais fundamentos: o risco inerente à atividade de provedor e a relação de consumo estabelecida entre o usuário e o provedor. A tese do risco inerente à atividade, o qual decorreria do art. $927 \S$ único do Código Civil, ${ }^{18}$ foi por longo período e, marcadamente antes da entrada em vigor do Marco Civil, utilizada pelos tribunais para determinar a responsabilidade do provedor. ${ }^{19}$ Com o passar do tempo, a jurisprudência do tribunal pacificou o entendimento em sentido contrário, entendendo pela inaplicabilidade do art. $927 \S$ único do Código Civil aos provedores de aplicação da internet. ${ }^{20}$

Por último, a terceira corrente defende a responsabilidade civil subjetiva dos provedores, partindo-se em duas vertentes: (i) a responsabilidade pelo não atendimento de notificação extrajudicial e (ii) pelo descumprimento de ordem judicial específica, nos exatos termos do art. 19 do Marco Civil. ${ }^{21}$

\footnotetext{
17 "No provider or user of an interactive computer service shall be treated as the publisher or speaker of any information provided by another information content provider". Em tradução livre: "(1) Tratamento como Divulgador ou Autor de Expressão: Nenhum provedor ou usuário de serviço interativo de computador deverá ser tratado como se divulgador ou autor fosse de qualquer informação disponibilizada por provedor de informações". ${ }_{18}$ STJ, $3^{\mathrm{a}}$ T., REsp 1.308.830/RS, Rel. Min. Nancy Andrighi, julg. 8.5.2012; TJRJ, 2 ${ }^{\mathrm{a}}$ C.C, Ap. Civ. 2009.001.14165, Rel. Des. Alexandre Câmara, julg. 8.4.2009.

${ }^{19}$ TJSP, $39^{a}$ V.C, Processo n ${ }^{\circ}$ 583.00.2006.243439-5, Juiz Ulysses de Oliveira Gonçalves Junior, julg. 6.3.2008.

20 "RESPONSABILIDADE CIVIL. SITE DE RELACIONAMENTO. MENSAGENS OFENSIVAS. A responsabilidade objetiva, prevista no art. 927, parágrafo único, do CC, não se aplica a empresa hospedeira de site de relacionamento no caso de mensagens com conteúdo ofensivo inseridas por usuários. O entendimento pacificado da Turma é que o dano decorrente dessas mensagens não constitui risco inerente à atividade dos provedores de conteúdo. A fiscalização prévia do teor das informações postadas pelo usuário não é atividade do administrador de rede social, portanto seu dever é retirar do ar, logo que for comunicado, o texto ou a imagem que possuem conteúdo ilícito, apenas podendo responder por sua omissão". (STJ, Informativo $\mathrm{n}^{\circ} 0460$. Precedentes citados: REsp 1.186.616/MG, publ. 31.8.2011; REsp 1.175.675/RS, publ. 20.9.2011; REsp 1.306.066/MT, julg. 17.4.2012).

21 "Art. 19. Com o intuito de assegurar a liberdade de expressão e impedir a censura, o provedor de aplicações de internet somente poderá ser responsabilizado civilmente por danos decorrentes de conteúdo gerado por terceiros
} 
Antes da entrada em vigor do Marco Civil, portanto, a jurisprudência pacífica do STJ era no sentido de que sob a ótica da diligência média que se espera do provedor, deve este adotar as providências estiverem ao seu alcance para retirada de conteúdos manifestamente ilegais sob pena de responsabilização subjetiva por culpa in omittend". ${ }^{22}$

Os críticos desta corrente alegam que (i) deixar que o provedor julgue se o conteúdo é adequado ou não criaria um empoderamento dos provedores, conforme aventado pelo próprio Superior Tribunal de Justiça, ${ }^{23}$ (ii) haveria um alto grau de subjetividade que o provedor de aplicações poderia conferir aos critérios de retirada dos conteúdos e (iii) retira da apreciação do poder judiciário da justeza ou não de determinada violação. Vejamos, portanto, as principais reflexões que merecem ser feitas acerca do regime instituído pelo Marco Civil.

\subsection{O regime de responsabilidade civil dos provedores de aplicações por danos} decorrentes de conteúdos gerados por terceiros: o art. 19 do Marco Civil da Internet

Distanciando-se da jurisprudência do Superior Tribunal de Justiça em vigor até então, ${ }^{24}$ o Marco Civil institui o regime de responsabilidade civil subjetiva pelo descumprimento de ordem judicial específica, rechaçando a legitimidade da notificação extrajudicial como instrumento hábil a deflagrar a responsabilidade civil subjetiva decorrente da omissão de retirada do material ofensivo de circulação, nos exatos termos da redação do artigo 19 do Marco Civil da Internet.

Trata-se da adoção da responsabilidade civil subjetiva do provedor, que será responsabilizado pelos conteúdos ofensivos gerados por terceiros tão e somente após descumprimento de ordem judicial específica e, somente, se preenchidos os demais requisitos do art. 19. Para a configuração da responsabilidade subjetiva deve-se preencher o pressuposto da obrigação de indenizar: o comportamento culposo (PEREIRA, 2016), conforme dicção

\footnotetext{
se, após ordem judicial específica, não tomar as providências para, no âmbito e nos limites técnicos do seu serviço e dentro do prazo assinalado, tornar indisponível o conteúdo apontado como infringente, ressalvadas as disposições legais em contrário. $\S 1^{\circ} \mathrm{A}$ ordem judicial de que trata o caput deverá conter, sob pena de nulidade, identificação clara e específica do conteúdo apontado como infringente, que permita a localização inequívoca do material.”

${ }^{22}$ STJ, $3^{\mathrm{a}}$ T., REsp 1.193.764/SP, Rel. Min. Nancy Andrighi, julg. 14.12.2010; STJ, $3^{\mathrm{a}}$ T., Agr. Reg. em REsp 1.309.891/MG, Rel. Min. Sidnei Beneti, julg. 26.6.2012.

${ }^{23}$ STJ, $3^{\text {a }}$ T., REsp 1.316.921/RJ, Rel. Min. Nancy Andrighi, julg. 26.6.2012.

${ }^{24}$ Esta posição anterior do STJ foi objeto de observação pelo Min. Luis Felipe Salomão, ao comentar a disparidade do Marco Civil com a construção jurisprudencial realizada pelo STJ até então: "segundo a nova lei de regência a responsabilidade civil do provedor de internet consubstancia responsabilidade por dano decorrente de descumprimento de ordem judicial, previsão que se distancia, em grande medida, da jurisprudência atual do STJ, a qual, para extrair a conduta ilícita do provedor, se contenta com a inércia após notificação extrajudicial." (STJ, RESp 1.512.647/MG, Rel. Min. Luis Felipe Salomão, Segunda Seção, julg. 13.5.2015).
}

Rev. de Direito, Governança e Novas Tecnologias | e-ISSN: 2526-0049 | Porto Alegre | v. 4 | n. 2 | p. 61 - 82 | Jul/Dez. 2018 
literal do art. 186 do Código Civil. O ato ilícito cometido pelo provedor de aplicações consiste em um ato omissivo, qual seja, a omissão na remoção do conteúdo de sua plataforma após determinação judicial neste sentido.

\subsubsection{O equívoco do locus privilegiado da liberdade contido no art. 19 do Marco Civil}

Ao estabelecer um mecanismo engessado, que cria uma proteção intensa para as sociedades empresárias que exploram redes sociais e reduz o grau de proteção que já vinha sendo fixado pela jurisprudência brasileira para os usuários da internet, o artigo 19, equivocadamente, privilegia o direito fundamental à liberdade de expressão em detrimento de outras garantias constitucionais,. Olvidou-se do fato de que os direitos fundamentais da pessoa humana (honra, privacidade, imagem, entre outros) também são tutelados pela Constituição em patamar não inferior à liberdade de expressão, de modo que recordar apenas "um lado da moeda" já no início do art. 19 representa má técnica legislativa. (SCHREIBER, 2015a).

A doutrina constitucionalista pátria se manifesta acerca da posição preferencial da liberdade no ordenamento. Luís Roberto Barroso (2004) entende que a liberdade, ainda que hierarquicamente igual a demais direitos fundamentais, goza de uma posição preferencial no sistema - preferred position - por ser ela pré-condição para exercício de outros direitos. A liberdade cria uma ligeira pressão sobre os demais direitos constitucionais, gozando, para Barroso, de posição preferencial no sistema. ${ }^{25}$

Essa posição preferencial implica, por exemplo, em matéria de liberdade de expressão, na "absoluta excepcionalidade da proibição prévia de publicações, reservando-se essa medida aos raros casos em que não seja possível a composição posterior do dano que eventualmente seja causado aos direitos da personalidade" (BARROSO, 2004, p. 20). Daniel Sarmento (2015) também se filia a essa corrente da posição preferencial da liberdade no confronto com os demais direitos da personalidade. Especificamente sobre o Marco Civil da Internet, defende que é também essa a orientação que se infere da lei, que positivou, como princípio da regulação da

\footnotetext{
${ }^{25}$ Neste sentido: "Entende-se que as liberdades de informação e de expressão servem de fundamento para o exercício de outras liberdades, o que justifica uma posição de preferência - preferred position - em relação aos direitos fundamentais individualmente considerados. Tal posição, consagrada originariamente Suprema Corte Americana, tem sido reconhecida pela jurisprudência do Tribunal Constitucional Espanhol e pela do Tribunal Constitucional Federal Alemão" (BARROSO, 2004, p. 19). No mesmo sentido: "Assim, a liberdade de expressão e informação, acrescida dessa perspectiva de instituição que participa de forma decisiva na orientação da opinião pública na sociedade democrática, passa a ser estimada como elemento condicionador da democracia pluralista e corno premissa para o exercício de outros direitos fundamentais." (FARIAS, 1996, p. 167).
}

Rev. de Direito, Governança e Novas Tecnologias | e-ISSN: 2526-0049 | Porto Alegre | v. 4 | n. 2 | p. 61 - 82 | Jul/Dez. 2018 
rede, "a garantia da liberdade de expressão, comunicação e manifestação do pensamento" (art. $3^{\circ}$, inciso I).

A posição de preferência de liberdade não nos parece compatível, seja com a unidade do ordenamento (BODIN DE MORAES, 2010, p. 9), seja com a dignidade da pessoa humana enquanto fundamento da República. É o que defende Ingo Sarlet (2015), ao analisar a teoria da preferred position. Para o autor, a atribuição de uma função preferencial à liberdade de expressão não é compatível com as peculiaridades do direito constitucional positivo brasileiro, que, nesse particular, diverge em muito do norte-americano e mesmo inglês.

Parece-nos que em qualquer hipótese em que o princípio da liberdade for confrontado com a dignidade da pessoa humana, não há dúvidas de que o pêndulo da balança deverá prevalecer para a tutela da dignidade, em homenagem à unidade do ordenamento e à cláusula geral de tutela da pessoa humana consubstanciada no art. $1^{\circ}$ III da Constituição da República. ${ }^{26}$ Ou ainda que não penda em favor da dignidade, não poderá pender em favor da liberdade por expressa ausência de fundamento constitucional para tanto. É nesse contexto, que Gustavo Tepedino (2009) aborda a premente necessidade de promover a dignidade da pessoa humana no ambiente de desafios tecnológicos. ${ }^{27}$

Analisando a eventual posição privilegiada do princípio da liberdade no ordenamento, e em um contexto no qual a dignidade da pessoa humana é paradigma jurídico que reformula a disciplina das liberdades existenciais, não se pode afirmar a priori a prevalência de um direito fundamental sobre o outro, sobretudo quando se escolhe a prevalência de um direito postos em

\footnotetext{
26 “No Direito Brasileiro, a previsão do inciso III do art. $1^{\circ}$ da Constituição, ao consagrar a dignidade humana o valor sobre o qual se funda a República, representa uma verdadeira cláusula geral de tutela de todos os direitos que da personalidade irradiam. Assim, em nosso ordenamento, o princípio da dignidade da pessoa humana atua como uma cláusula geral de tutela e promoção da dignidade em suas mais diversas manifestações". (BODIN DE MORAES, 2016, p. 128). Ainda neste sentido: "Consagrada como valor basilar do ordenamento jurídico, a dignidade da pessoa humana, insculpida no art. $1^{\circ} \mathrm{III}$ da $\mathrm{CF}$, remodela as estruturas e a dogmática do direito civil brasileiro, operando a funcionalização das situações jurídicas patrimoniais às existenciais, de modo a propiciar o pleno desenvolvimento da pessoa humana". (TEPEDINO, 2009, p. 12).

"Art. $1^{\circ} \mathrm{A}$ República Federativa do Brasil, formada pela união indissolúvel dos Estados e Municípios e do Distrito Federal, constitui-se em Estado Democrático de Direito e tem como fundamentos: (...) I - a soberania; II - a cidadania; III - a dignidade da pessoa humana".

27 "O paradoxo de se viver em uma sociedade em que a revolução tecnológica produz, em sua esteira, a mais não poder recrudesce a necessidade de preservação e promoção da pessoa humana nas relações privadas, independentemente do tamanho ou do papel do Estado (assistencialista ou regulamentar). Anuncia-se, pois, uma árdua agenda para o Direito Civil com três preocupações centrais: (i) a compressão atual da metodologia direito civil-constitucional, que supere a mera percepção topográfica de uma mudança de técnica legislativa, (ii) a construção de uma nova dogmática do direito privado, com coerência axiológica em torno da unidade do ordenamento; e (iii) a fidelidade ao compromisso metodológico, a despeito das mudanças e políticas e econômicas que alteram o papel do Estado na sociedade e da crescente pluralidade de fontes normativas - tanto do ponto de vista nacional como supranacional". (TEPEDINO, 2009, p. 22).
}

Rev. de Direito, Governança e Novas Tecnologias | e-ISSN: 2526-0049 | Porto Alegre | v. 4 | n. 2 | p. 61 - 82 | Jul/Dez. 2018 
jogo como ponto de partida para o intérprete (BARBOSA; CASTRO, 2017, p.3), de modo que a noção de prevalência não pode ser um dado a priori.

Maria Celina Bodin de Moraes e Eduardo Nunes de Souza (2017), ao tratarem da legalidade do ensino domiciliar no Brasil, analisam a eventual posição de preferência da liberdade no ordenamento brasileiro. Para os autores, a assunção da primazia do princípio da liberdade sobre outros direitos é um equívoco metodológico, sendo preciso ponderar a liberdade com outros princípios, tais como a solidariedade social e demais corolários da dignidade humana.

Inexiste hierarquia entre direitos fundamentas ou princípios constitucionais no texto constitucional de modo a privilegiar o princípio de liberdade de expressão em detrimento do princípio da dignidade da pessoa humana. Ao oposto disto: a metodologia da constitucionalização do direito civil, ao impor a incidência direta das normas constitucionais nas relações privadas - como é a relação entre usuário das redes sociais e o provedor - impõe a leitura do sistema da responsabilidade civil a favor da pessoa humana (PERLINGIERI, 1999). Pelo dever de unidade no ordenamento, devem todas as normas centrarem-se sobre os valores constitucionais, ainda que se diversifiquem suas fontes e se especializem os seus setores (SCHREIBER, 2013). O Marco Civil da Internet não pode, portanto, distanciar-se dessa obrigação - como o fez ao privilegiar a proteção da liberdade de expressão em detrimento da tutela da pessoa. ${ }^{28}$ Ao se propor um modelo alternativo de responsabilidade civil solidária entre o provedor e o usuário, portanto, busca-se recentralizar o Marco Civil da Internet à unidade do ordenamento.

Resgate-se que a doutrina da preferred positivon tem origem no constitucionalismo norte americano, incompatível com o sistema jurídico da civil law brasileiro. Enquanto o sistema romano-germânico é marcado pela interpretação do ordenamento, dotados de unidade e coerência, os sistemas da common law baseiam-se nos casos concretos (case law) poucos codificados, dando-se primazia à experiência nos tribunais. A simples importação da posição

\footnotetext{
${ }^{28}$ Trata-se, em verdade, da hipótese de conflito entre direitos fundamentais - o da liberdade o da dignidade da pessoa humana - cujo método de solução não está entre aqueles tradicionais da hermenêutica clássica, conforme defende Luis Roberto Barroso (2001), ao tratar das novas técnicas de interpretação constitucional. Segundo o constitucionalista: "O Direito, como se sabe, é um sistema de normas harmonicamente articuladas. Uma situação não pode ser regida simultaneamente por duas disposições legais que se contraponham. Para solucionar essas hipóteses de conflito de leis, o ordenamento jurídico se serve de três critérios tradicionais: o da hierarquia - pelo qual a lei superior prevalece sobre a inferior -, o cronológico - onde a lei posterior prevalece sobre a anterior - e o da especialização - em que a lei específica prevalece sobre a lei geral. Estes critérios, todavia, não são adequados ou plenamente satisfatórios quando a colisão se dá entre normas constitucionais, especialmente entre princípios constitucionais, categoria na qual devem ser situados os conflitos entre direitos fundamentais." (BARROSO, 2001, p. 32).
}

Rev. de Direito, Governança e Novas Tecnologias | e-ISSN: 2526-0049 | Porto Alegre | v. 4 | n. 2 | p. 61 - 82 | Jul/Dez. 2018 
preferencial do princípio da liberdade, portanto, é temerária (KONDER, 2015, p.36) ${ }^{29}$. Como advertiu Maria Celina Bodin de Moraes (2014), a lógica do modelo anglo-saxão é simplesmente diferente demais da lógica do sistema romano-germânico para que uma aproximação acrítica possa sair impune.

A reflexão da equivocada posição preferencial que se atribui ao princípio da liberdade é, portanto, relevante para se repensar o principal fundamento dado ao regime da responsabilidade civil subjetiva adotada pelo Marco Civil da Internet: a suposta tutela irrestrita da liberdade de expressão. Tal fundamento mostra-se frágil, e, portanto, frágil também é o sistema que nele se ampara, ao levar-se em conta (i) a unidade do ordenamento; (ii) a inexistência de hierarquia entre normas e princípios constitucionais; (iii) a impossibilidade de importação para o sistema brasileiro da concepção norte-americana da liberdade, por completa incompatibilidade entre os sistemas da civil law e o modelo de common law.

Na busca da proteção dos direitos fundamentais, como privacidade e intimidade, dizse que é preciso regular o segmento da internet de forma atenta à necessidade de preservação da inovação no ambiente digital, não demorando muito o ente a regular o segmento, considerando que "postergar a intervenção regulatória, ainda que por um prazo determinado, é postergar também seus efeitos benéficos e arriscar a perpetuação de situações de injustiça ou a produção de resultados indesejados ou menos eficiente" (BAPTISTA; KELLER, 2016, p. 146). O Direito, portanto, não deve ser enxergado como o inimigo da liberdade, o que seria um equívoco metodológico profundo na visão de Schreiber (2015a), na medida em que só em um ambiente normatizado o exercício da liberdade pode ocorrer sem o receio de abusos, que representam a sua própria negação.

Esse raciocínio, pois, aplica-se integralmente ao se pensar a liberdade de expressão no âmbito do Marco Civil da Internet. Ao se buscar a construção de um modelo de responsabilidade civil que assegure melhores formas de proteção à vítima de danos injustos, não se tolhe a liberdade de expressão de forma direta e imediata com a retirada de conteúdos manifestamente ilegais do ar de redes sociais de forma flagrante. O que se procura é qualificar a exploração econômica e social desse meio.

\footnotetext{
${ }^{29}$ Bem adverte o autor: "Se todo instituto jurídico existe e ganha significado dentro de um ordenamento específico, para compreender seu conceito e alcance deve-se ter em mente o todo do qual ele faz parte, analisando-o em relação com os princípios que lhe são sentido, com os demais institutos com que faz fronteira, com as regras que viabilizam sua aplicação e na forma pela qual é interpretado". (...) Sob essa perspectiva, portanto, a retirada de um instituto de seu ordenamento de origem e sua inserção e aplicação em outro ordenamento não importa apenas seu reposicionamento, mas implica a redefinição de seu próprio conceito, de seu alcance e de seus efeitos.” (KONDER, 2015, p.36).
}

Rev. de Direito, Governança e Novas Tecnologias | e-ISSN: 2526-0049 | Porto Alegre | v. 4 | n. 2 | p. 61 - 82 | Jul/Dez. 2018 
O Marco Civil traz, entretanto, duas exceções a este regime: os casos de pornografia de vingança, previstos no artigo 21, e os casos de veiculação de materiais que potencialmente infrinjam Direitos Autorais - hipótese que não trataremos com profundidade neste trabalho. ${ }^{30}$

\subsection{A existência de mecanismos técnicos que viabilizam a exclusão de conteúdos pelo provedor de aplicações sem a indicação precisa de URL}

O art. 19 do Marco Civil contém, ainda, outro equívoco que praticamente inviabiliza a remoção de conteúdo pelo usuário: a necessidade de indicação precisa de URL que localize o conteúdo. Em relação ao trecho "no âmbito e nos limites técnicos do seu serviço" do art. 19, a análise dos termos e condições dos provedores de aplicações mostra a plena capacidade técnica para a retirada de tais conteúdos do ar, senão vejamos.

Em certas demandas judiciais onde se discute a responsabilidade civil pela (não) exclusão de conteúdos lesivos das redes, os provedores de aplicação, por praxe, aduzem não disporem de mecanismos tecnológicos necessários para a exclusão destes conteúdos. Tome-se por base, a título exemplificativo, as alegações da Google nos autos do Recurso Especial 1.512.647 ${ }^{31}$ que à despeito do pedido de exclusão de anúncios de material protegido por direitos autorais do Orkut, aduziu que "não haveria como a Google fornecer dados de IP de usuários ou remover conteúdo violador de direitos autorais sem a indicação precisa da URL ${ }^{32}$ na qual estaria hospedado tal conteúdo. ${ }^{33}$

\footnotetext{
${ }^{30}$ Acerca da responsabilidade civil do provedor de paliações por veiculação de materiais que infrinjam Direito Autoral, deve-se tomar em conta o disposto do art. $19 \S 2^{\circ} \mathrm{e}$ art. 31 do Marco Civil da Internet. Nota-se, à luz dos arts. $19 \S 2^{\circ}$ e art. 31, ambos do Marco Civil, que o legislador optou por remeter a matéria para à Lei de Direitos Autorais (Lei no 9.610/98). A aplicabilidade do Marco Civil para a tutela dos Direitos Autorais depende, portanto, da edição de regulamentação superveniente. Em 11 de maio de 2016, foi editado o Decreto $\mathrm{n}^{\circ}$ 8.771/16 para regulamentar o Marco Civil da Internet. Tal decreto abordou a discriminação de pacotes de dados na internet, proteção de dados pessoais e cadastrais, omitindo-se acerca da regulamentação de que trata o art. $19 \S 2^{\circ}$ do Marco Civil.

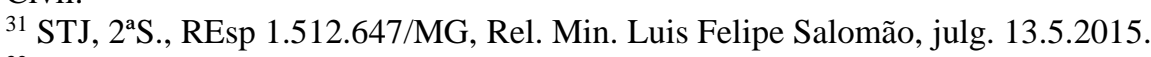

${ }^{32}$ URL é a abreviatura de Uniform Resource Locator, ou Localizador Padrão de Recursos, em português, designando o endereço de um recurso disponível em uma rede, ou seja, é o endereço virtual de um arquivo, uma impressora ou outro acessório disponível numa rede, seja esta corporativa (intranet) ou a internet.

${ }^{33}$ A ausência da URL como suposto impedimento técnico para a retirada do material ofensivo também já foi arguida pelo Facebook, em diversas demandas judiciais. Vide, por exemplo, o STJ, $3^{\mathrm{a}}$ T., AREsp 927782/STJ, Rel. Min. Ricardo Villas Bôas Cueva, publ. 28.6.2016, onde asseverou-se que " A jurisprudência do STJ, em harmonia com o art. 19, $\S 1^{\circ}$, da Lei no 12.965/2014 (Marco Civil da Internet), entende necessária a notificação judicial ao provedor de conteúdo ou de hospedagem para retirada de material apontado como infringente, com a indicação clara e específica da URL - Universal Resource Locator. No mesmo sentido: STJ, $2^{\mathrm{a}}$ S., REsp 1.512.647/MG, Rel. Ministro Luis Felipe Salomão, julg. 13.5.2015, de onde extrai-se o trecho: "8. Quanto à obrigação de fazer - retirada de páginas da rede social indicada -, a parte autora também juntou à inicial outros documentos que contêm, de forma genérica, URLs de comunidades virtuais, sem a indicação precisa do endereço
} 
Tais alegações vêm sendo reiteradas por provedores de aplicações em demandas judiciais, o que em nosso entendimento não se coaduna com o standard de conduta dos provedores que pode ser extraído dos seus próprios termos de uso. A análise dos termos e condições de uso do Facebook ${ }^{34}$ - documento disponível ao acesso público e que regulamenta o relacionamento entre usuário e provedor - revela que o provedor poderá a qualquer momento retirar do ar o material que, de acordo com a análise unilateral e discricionária do provedor, possa ser considerado ofensivo. Assim dispõem os termos e usos. ${ }^{35}$

Vejamos, ainda, os Termos de Serviço do Twitter (2016), que também são reveladores do possível standard de conduta deste provedor de aplicação acerca das ferramentas e do comportamento que tal entidade pode assumir ante um conteúdo considerado ilegítimo. ${ }^{36}$

A rápida leitura dos termos e condições destes provedores revela que os provedores dispõem, claramente, de ferramentas tecnológicas para que, per si, e sem que o usuário forneça informações adicionais, nem mesmo a URL, seja retirado qualquer conteúdo da rede que seja reputado como violador de direitos de terceiros, caindo por terra as limitações tecnológicas alegadas pelos servidores ao requererem a apresentação precisa das URL's, considerando a notória existência de ferramentas de identificação de conteúdo sem a necessidade de indicação

interno das páginas nas quais os atos ilícitos estariam sendo praticados. Nessas circunstâncias, a jurisprudência da Segunda Seção afasta a obrigação do provedor, nos termos do que ficou decidido na Rcl 5.072/AC, Rel. p/ acórdão Ministra Nancy Andrighi, DJe 4/6/2014”.

${ }^{34}$ Pode-se dizer que os termos e condições de uso - conjunto de regras estabelecidas unilateralmente pelo provedor de aplicações aos usuários para uso de suas plataformas - têm natureza jurídica de contrato de adesão. Para Caio Mário (2004, p. 72), "chamam-se de contratos de adesão aqueles que não resultam do livre debate entre as partes, mas provêm do fato de uma delas aceitar tacitamente cláusulas e condições previamente estabelecidas pela outra". A utilidade prática de se investigar a natureza jurídica destes instrumentos é determinar a incidência da disciplina específica dos contratos de adesão a esses instrumentos, mormente o comando contido nos arts. 423 e 424 do Código Civil. A jurisprudência já se manifestou quanto à abusividade de quaisquer condições constantes dos termos e condições de uso do Facebook nas hipóteses em que se viole a dignidade e demais direitos da personalidade. Foi o que o Tribunal de Justiça do Estado do Parará decidiu ao analisar se para uso do aplicativo Lulu seria suficiente a autorização de acesso aos dados pessoais do usuário por meio da adesão aos termos de uso do Facebook. (TJPR, 2 J.E.C de Maringá, Ação 0015216-72.2013.8.16.0018, Juiz Fernando Swain Ganem, julg. 18.6.2015).

${ }^{35}$ Termos de uso do Facebook: "5. PROTEÇÃO DOS DIREITOS DE OUTRAS PESSOAS. (...) 3. Nós podemos remover qualquer conteúdo ou informação publicada por você no Facebook se julgarmos que isso viola esta declaração ou nossas políticas. 4. Se removermos seu conteúdo por infringir os direitos autorais de alguém, e você acreditar que o removemos por engano, forneceremos a você a oportunidade de recorrer." (Declaração de Direitos e Responsabilidades do Facebook. Última revisão em 30 de janeiro de 2015 . Disponível em https://www.facebook.com/legal/terms. Acessado em 18 de setembro de 2016).

36 “8. RESTRIÇÕES DE CONTEÚDO E UTILIZAÇÃO DOS SERVIÇOS

(...). O Twitter reserva-se o direito (não havendo a obrigação) de a qualquer momento, excluir ou recusar a distribuir ou disponibilizar qualquer conteúdo nos serviços, (...), não podendo ser responsabilizado a qualquer título perante você em consequência destes atos. Reservamo-nos ainda os direitos de acesso, leitura, preservação e divulgação de qualquer informação que, na nossa opinião, acreditamos ser necessária para (...) (iii) detectar, prevenir ou de qualquer forma lidar com situações de fraude, assim como com questões de segurança ou de natureza técnica (...).”. Declaração de Termos de Serviços do Twitter. Em vigor desde 27 de janeiro de 2016. Disponível em https://twitter.com/tos?lang=pt. Acessado em 19 de setembro de 2016.

Rev. de Direito, Governança e Novas Tecnologias | e-ISSN: 2526-0049 | Porto Alegre | v. 4 | n. 2 | p. 61 - 82 | Jul/Dez. 2018 
específica de URL. ${ }^{37}$ Tendo isto em mente, parece-nos infundada e distante da melhor tutela a ser oferecida aos direitos da personalidade a exigência legal contida no artigo $19 \S^{\circ}$ do Marco Civil da Internet, que impõe como requisito para a ordem legal de retirada do conteúdo do ar, que a sentença "deverá conter, sob pena de nulidade, identificação clara e específica do conteúdo apontado como infringente, que permita a localização inequívoca do material”.

O Superior Tribunal de Justiça, em diversas demandas, assentou o entendimento de que é necessária a indicação de URL's específicas para a retirada de material ofensivo da rede, na forma estabelecida no art. $19 \S 1^{\circ}$ do Marco Civil da Internet ${ }^{38}$ - interpretação esta que, ao nosso entender e com as devidas vênias à Corte, não se coadunam com a dignidade da pessoa humana no ápice do ordenamento jurídico e a axiologia que dela deve decorrer.

A jurisprudência eleitoral vem abrandando esta exigência do Marco Civil da Internet e substituindo a exigência de apresentação da URL pela simples cópia da página onde conste a ofensa alegada pela vítima. ${ }^{39}$ A justiça eleitoral vem temperando a aplicação do art. $17, \mathrm{IV}$, 'b' da Resolução TSE n⿳ 23.462/15, no sentido de que "o que se exige é, apenas, que o requerimento seja feito com elementos suficientes que permitam identificar, previamente, o autor e a extensão do conteúdo produzido, de modo a tornar a medida judicial exequível e evitar que o provedor de internet funcione como um verdadeiro censor prévio de conteúdos formulados por seus

\footnotetext{
${ }^{37}$ A despeito das ferramentas tecnológicas existentes para identificar um conteúdo sem que se indique sua URL específica, a Microsoft desenvolveu o recurso chamado "PhotoDNA", capaz de fazer um DNA de qualquer material, um produto usado pelo Facebook e pelo Twitter. 'O PhotoDNA, criado pela Microsoft especialmente para encontrar imagens de exploração sexual infantil, se baseia no conceito de hash, sequência de caracteres obtida a partir de um cálculo sobre o arquivo da imagem. Funciona assim: a imagem é convertida para preto e branco, depois redimensionada e então dividida em várias células. Cada uma dessas células tem suas cores e gradientes analisados individualmente, gerando o DNA da foto. Caso um arquivo gere um hash já registrado previamente em um banco de dados associado a a imagens de teor pedófilo, um alerta é gerado". Disponível em < https://tecnoblog.net/162694/photodna-pornografia-infantil-microsoft/> . Acessado em 08 de setembro de 2017. Vide, também, reportagem obtida no site da Microsoft, intitulada "Microsoft's PhotoDNA: Protecting children and businesses in the cloud". Disponível em < https://news.microsoft.com/features/microsofts-photodnaprotecting-children-and-businesses-in-the-cloud/>. Acessado em 08 set. 2017.

${ }^{38}$ Vide, neste sentido: "Recurso Especial. Obrigação de fazer e reparação civil. Danos morais e materiais. Provedor de serviços de internet. Rede social "ORKUT". Responsabilidade subjetiva. Controle editorial. Inexistência. Apreciação e notificação judicial. Necessidade. art. 19, $\S 1^{\circ}$, da lei $\mathrm{n}^{\circ}$ 12.965/2014 (marco civil da internet). Indicação da URL. Monitoramento da rede. Censura prévia. Impossibilidade. Ressarcimento dos honorários contratuais. Não cabimento. (...) 4. A jurisprudência do STJ, em harmonia com o art. 19, $\S 1^{o}$, da Lei $n^{o}$ 12.965/2014 (Marco Civil da Internet), entende necessária a notificação judicial ao provedor de conteúdo ou de hospedagem para retirada de material apontado como infringente, com a indicação clara e específica da URL Universal Resource Locator." Grifos nossos. (STJ, $3^{\text {a }}$ T., REsp 1.568.935/RJ, Rel. Min. Ricardo Villas Bôas Cueva, julg. 5.4.2016). Ainda, no mesmo sentido: Rcl 5.072/AC, $2^{\text {a S} ., ~ R e l . ~ p / ~ a c o ́ r d a ̃ o ~ M i n . ~ N a n c y ~ A n d r i g h i, ~ D J e ~}$ 4.6.2014; STJ, 2 ${ }^{\mathrm{a} S}$., REsp 1.512.647/MG, Rel. Min. Luis Felipe Salomão, julg. 13.5.2015).

${ }^{39}$ Veja-se o disposto no art. 17, IV, alínea "b" da Resolução TSE no 23.462/15: Art. 17. Serão observadas, ainda, as seguintes regras no caso de pedido de direito de resposta relativo à ofensa veiculada: IV - em propaganda eleitoral pela Internet: a) o pedido poderá ser feito enquanto a ofensa estiver sendo veiculada, ou no prazo de setenta e duas horas, contado da sua retirada; b) a inicial deverá ser instruída com cópia impressa da página em que foi divulgada a ofensa e com a perfeita identificação de seu endereço na Internet (URL); (Grifos nossos).
}

Rev. de Direito, Governança e Novas Tecnologias | e-ISSN: 2526-0049 | Porto Alegre | v. 4 | n. 2 | p. 61 - 82 | Jul/Dez. 2018 
usuários". ${ }^{40}$ Trata-se de uma interpretação criativa, louvada pela metodologia do direito civilconstitucional, que está a serviço da realização de um valor constitucional, qual seja, a garantia da indenização integral por meio da facilitação de indicação de danos injustos em procedimentos judiciais. $^{41}$

Nos casos de danos à personalidade, é comum que os conteúdos ofensivos se multipliquem entre diversos links da internet, de modo que seria tecnicamente inviável ao usuário e desmedidamente gravoso exigir que se indique todos os links pelos quais o conteúdo tenha circulado. Atenta a essa inviabilidade prática e ônus desmesurado que atualmente se impõe ao usuário, e ao se requerer a indicação da URL específica, a posição do Superior Tribunal de Justiça antes da entrada em vigor do Marco Civil, era de que "o provedor de internet, ainda em sede liminar, deve retirar informações difamantes a terceiros manifestadas por seus usuários, independentemente da indicação precisa, pelo ofendido, das páginas em que foram veiculadas as ofensas (URLs)." ${ }^{42}$ A matéria também foi objeto de manifestação pelo Conselho de Justiça Federal, assentada no Enunciado 554 da VI Jornada de Direito Civil. ${ }^{43}$ Ao considerar os danos na internet é preciso, primeiramente, fazer cessar o dano, visto que a rapidez com que as informações são replicadas e disponibilizadas na internet pode tornar inútil a prestação jurisdicional. Além disso, a não exigência de todos os links específicos visa preservar a própria efetividade da jurisdição, principalmente quando envolve antecipações dos efeitos da tutela em que se determina o bloqueio da informação, e não apenas de um link específico.

Vê-se, portanto, que o Marco Civil novamente andou na contramão da jurisprudência e da doutrina que o precederam, apresentando mais um retrocesso ao impor maiores

\footnotetext{
${ }^{40}$ Vide TJES, $2^{\text {a }}$ C.C., Agr. de Inst. 00014593220158080028, Rel. Des. Carlos Simões Fonseca, julg. 19.5.2015. No mesmo sentido: "Eleições 2016. Recurso Eleitoral. Propaganda eleitoral irregular. Facebook. Conteúdo Ofensivo. (.....). 4. A determinação ao Recorrente para a retirada imediata do ar de conteúdo ofensivo que extrapola a legítima manifestação do pensamento, identificável por URL específica constante de documento que acompanha a inicial deve ser cumprida imediatamente sob pena de imposição de multa. (...) Hipótese concreta em que, pelos elementos que instruem a inicial, é perfeitamente possível divisar a URL, não havendo aplicação do Art. 19 do Marco Civil da Internet, pois a regra eleitoral específica contida na Resolução TSE $n^{\circ}$ 23.462/15, em seu art. 17, IV, alínea “b”, prevalece sobre aquela". (TRE/ES, RE 44-61.2016.6.08.0055, Rel. Juiz Adriano Athayde Coutinho, julg. 29.11.2016).

${ }^{41}$ Nesse sentido, leciona Anderson Schreiber (2016, p. 14) "O direito civil-constitucional não aprisiona o intérprete na literalidade da lei, nem o deixa livre para criar o direito a partir dos seus próprios instintos e opiniões: reconhecelhe um papel criativo, mas sempre vinculado à realização dos valores constitucionais. Por meio dos princípios, valores sociais e culturais invadem claramente o mundo do direito, mas mediados pelos significantes que os expressam e por um cuidadoso mecanismo científico - posto argumentativo - de aplicação."

${ }^{42}$ STJ, $4^{a}$ T., REsp 1.175.675/RS, Rel. Min. Luis Felipe Salomão, julg. 9.8.2011.

43 "Enunciado 554 - Independe de indicação do local específico da informação a ordem judicial para que o provedor de hospedagem bloqueie determinado conteúdo ofensivo na internet."
}

Rev. de Direito, Governança e Novas Tecnologias | e-ISSN: 2526-0049 | Porto Alegre | v. 4 | n. 2 | p. 61 - 82 | Jul/Dez. 2018 
dificuldades e entraves práticos para a tutela da dignidade em hipóteses de divulgação de materiais ofensivos na internet.

As informações correm em velocidades colossais, se multiplicando por páginas, comunidades, links, likes e posts novos em velocidades inimagináveis, fugindo ao lesado a aptidão técnica para indicar a localização precisa destes conteúdos. Não se pode limitar a tutela dos direitos da personalidade sob a alegação de impossibilidades técnicas, que não existem e funcionam como um argumento acessório ao cheque em branco dado aos provedores para operarem no Brasil.

Caso o provedor mantenha-se inerte quanto à notificação, utilizando-se do benefício legal da necessidade de sentença judicial contida no art. 19 do Marco Civil, ou caso o provedor lhe responda alegando ser impossível a retirada do conteúdo sem a indicação precisa e detalhada de todos os possíveis locais (URL's) onde estejam localizados os post, reposts e compartilhamentos, ou, ainda, caso tenha de se buscar o judiciário para ajuizar uma demanda judicial requerendo a tutela de urgência para a retirada do conteúdo e esta seja negada em razão do descumprimento da exigência de indicação de URL contida no $§ 1^{\circ}$ do art. 19, será tarde demais. Os inúmeros passos burocráticos que o Marco Civil lhe impôs ceifaram as possibilidades concretas de retirar da rede o material que lhe ofendia. Com efeito, conclui-se que a exigência judicial de indicação precisa de URL não se coaduna com a tutela da dignidade da pessoa humana, privilegiando a técnica da subsunção legal e a interpretação gramatical do art. $19 \S 1^{\circ}$ do Marco Civil em detrimento da interpretação axiológica e sistemática da cláusula geral de tutela da dignidade da pessoa humana disposta no art. $1^{\circ}$ III da Carta da República para a tutela de situações existenciais no meio digital (SCHREIBER, 2015a, p. 277-305).

\section{SÍNTESE CONCLUSIVA}

Nossas conclusões parciais, portanto, são as seguintes: a jurisprudência do Superior Tribunal de Justiça, antes da entrada em vigor do Marco Civil da Internet, responsabilizava o provedor pela inércia caso este não retirasse o conteúdo ofensivo do ar após ser notificado pela vítima; o Marco Civil adota teoria diversa da jurisprudência até então vigente e impõe a necessidade de ordem judicial específica para a retirada de conteúdo; o Marco Civil privilegia a liberdade de expressão em detrimento de outros direitos constitucionais, tal qual a dignidade da pessoa humana, não obstante inexistir tratamento superior para a liberdade no texto Constitucional e não obstante a dignidade da pessoa humana ser um dos cinco fundamentos do 


\section{BREVES NOTAS SOBRE A RESPONSABILIDADE CIVIL DOS PROVEDORES DE APLICAÇÕES DE INTERNET NA PERSPECTIVA CIVIL-CONSTITUCIONAL}

modelo de Estado eleito pelo constituinte (art. $1^{\circ}$ da CR/88); o art. 19 do Marco Civil é inconstitucional por afronta ao art. $5^{\circ} \mathrm{X}$ da $\mathrm{CR} / 88^{44}$; é imperioso construir novos modelos de responsabilidade civil do provedor para efetivar a proteção da pessoa na internet.

A inovação legislativa, apesar de bem intencionada quanto à ampliação da tutela da liberdade de expressão, representa um retrocesso em relação ao grau de tutela da dignidade da pessoa humana no ambiente digital. Isto porque impõe-se a tutela da liberdade em detrimento à dignidade, assim como impõe-se ao usuário a obrigação (e não a faculdade) de buscar amparo no Poder Judiciário para deflagrar-se a responsabilidade do provedor, sendo o Poder Judiciário ineficiente e moroso em relação ao dinamismo das relações travadas na Internet.

O Marco Civil, ao exigir a indicação precisa de URL do conteúdo ofensivo em seu art. $19 \S 1^{\circ}$, constitui um grande ônus técnico à pretensão do usuário em ver excluídos os materiais ofensivos da internet, uma vez que são os provedores detêm de meios técnicos para localizar os conteúdos ofensivos (ainda que sem a indicação específica de URL), culminando em um entrave desproporcional, irrazoável e excessivamente gravoso aos usuários vítimas de um dano injusto na Internet.

A responsabilidade civil dos provedores anda na contramão do processo de flexibilização dos filtros tradicionais. Enquanto a responsabilidade civil contemporânea caminha rumo à erosão de seus filtros, o Marco Civil da Internet representa um retrocesso social em termos de proteção à pessoa ao não se imputar a responsabilização solidária aos provedores em relação ao conteúdo ofensivo postado por terceiros. Com isso, tem-se a necessidade de repensar a exigência de judicialização da matéria trazida pela inovação legislativa, uma vez a interpretação do art. 19 do Marco Civil da Internet conforme a Constituição Federal nos remete à proteção da dignidade humana como fundamento da nossa República.

Dispensando-se a ordem judicial específica e contentando-se com a mera notificação extrajudicial para caracterizar a responsabilidade civil solidária dos provedores, em caso de omissão, pode-se dar concretude à proteção de direitos extrapatrimoniais dos usuários vítimas de conteúdos ofensivos gerados na Internet, evitando assim, danos irreversíveis para a dignidade das vítimas.

\footnotetext{
44 “A criação, por lei ordinária, de condicionantes ou limites à responsabilidade civil por violação a esses direitos afigura-se inconstitucional, na medida em que restringiram uma tutela que o Constituinte quis plena e integral, a ponto de enuncia-la sem qualquer menção à atuação ulterior do legislador. Assim, ao condicionar a reparação do dano decorrente de violações que podem atingir a honra, a privacidade e a imagem da pessoa humana ao prévio ajuizamento de demanda judicial, o art. 19 da Lei 12.965 afronta o art. $5^{\circ} \mathrm{X}$ da Constituição da República". (SCHREIBER, 2015a, p. 293).
}

Rev. de Direito, Governança e Novas Tecnologias | e-ISSN: 2526-0049 | Porto Alegre | v. 4 | n. 2 | p. 61 - 82 | Jul/Dez. 2018 


\section{REFERÊNCIAS BIBLIOGRÁFICAS}

BAPTISTA, Patrícia; KELLER; Clara Iglesias. Por que, quando e como regular as novas tecnologias? Os desafios trazidos pelas inovações disruptivas. RDA - Revista de Direito Administrativo, v. 273. set./dez. 2016.

BARBOSA, Fernanda Nunes; CASTRO, Thamis Dalsenter Viveiros de. Dilemas da liberdade de expressão e da solidariedade. Civilistica.com. Rio de Janeiro, a. 6, n. 2, 2017. Disponível em: <http://civilistica.com/dilemas-da-liberdade-de-expressao/>. Acesso 24.6.2018.

BARROSO, Luís Roberto. Colisão entre liberdade de expressão e direitos da personalidade: critérios de ponderação. interpretação constitucionalmente adequada do código civil e da lei de imprensa. In: Revista de Direito Administrativo, no 235. Jan/Mar 2004. Rio de Janeiro

BARROSO, Luís Roberto. Temas de direito constitucional, t. II. Rio de Janeiro: Renovar: 2001.

BODIN DE MORAES, Maria Celina. Danos à pessoa humana. Rio de Janeiro: Renovar, 2003.

BODIN DE MORAES, Maria Celina. Perspectivas a partir do direito civil-constitucional. Direito civil contemporânea. Novos problemas à luz da legalidade constitucional. TEPEDINO, Gustavo (org). São Paulo: Atlas, 2008.

BODIN DE MORAES, Maria Celina. Na Medida da Pessoa Humana: Estudos de direito civil-constitucional. Rio de Janeiro: Renovar, 2010.

BODIN DE MORAES, Maria Celina. Professores ou juízes? Editorial. Civilistica.com. Rio de Janeiro, a. 3, n. 2, jul.-dez./2014. Disponível em: <http://civilistica.com/professores-oujuizes/>. Acesso em: 15 dez. 2017.

BODIN DE MORAES, Maria Celina. Ampliando os direitos da personalidade. In: Na medida da pessoa humana: estudos de direito civil constitucional. $1^{\text {a }}$ reimpressão. Rio de Janeiro: Editora Processo, 2016.

BODIN DE MORAES, Maria Celina; SOUZA, Eduardo Nunes de. Educação e cultura no Brasil: a questão do ensino domiciliar. Civilistica.com. Rio de Janeiro, a. 6, n. 2, 2017. Disponível em: <http://civilistica.com/educacao-e-cultura-no-brasil/>. Acesso em 08 jan. 2018

FARIAS, Edilsom Pereira de. Colisão de direitos - a honra, a intimidade, a vida privada e a imagem versus a liberdade de expressão e informação. Porto Alegre: Sergio Fabris Editor, 1996.

FISS, Owen M. A ironia da liberdade de expressão: regulação e diversidade na esfera pública. Tradução e prefácio: Gustavo Binembojm e Caio Mário da Silva Pereira Neto. Rio de Janeiro: Renovar, 2005.

Rev. de Direito, Governança e Novas Tecnologias | e-ISSN: 2526-0049 | Porto Alegre | v. 4 | n. 2 | p. 61 - 82 | Jul/Dez. 2018 
HESPANHA, António Manuel. Cultura jurídica europeia: síntese de um milênio. Florianópolis: Boiteux, 2005, passim.

LOBO, Paulo. A constitucionalização do Direito Civil Brasileiro. In TEPEDINO, Gustavo (org.). Direito civil contemporâneo: novos problemas à luz da legalidade constitucional: anais do Congresso Internacional de Direito Civil-Constitucional da Cidade do Rio de Janeiro. São Paulo: Atlas, 2008.

KONDER, Carlos Nelson. Apontamentos iniciais sobre a contigencialidade dos institutos de direito civil. In Direito civil. MONTEIRO FILHO, Carlos Edison do Rêgo (org.) Rio de Janeiro: Freitas Bastos, 2015, p. 31-48.

MONTEIRO FILHO, Carlos Edison do Rêgo. Rumos cruzados do Direito Civil Pós-1988 e do Constitucionalismo de Hoje. In TEPEDINO, Gustavo (org.). Direito civil contemporâneo: novos problemas à luz da legalidade constitucional: anais do Congresso Internacional de Direito Civil-Constitucional da Cidade do Rio de Janeiro. São Paulo: Atlas, 2008, p. 262281.

NETO, Mario Furnaleto; GARCIA, Bruna Pinotti. Da guarda de registro de acesso a aplicações de internet na provisão de aplicações. In: DE LUCCA, Newton; SIMÃO FILHO; Adalberto; LIMA, Cíntia Rosa Pereira de (coords). Direito \& Internet - Tomo II: Marco Civil da internet (Lei n⿳0 12.965/2014). São Paulo: Quartier Latin, 2015.

PEREIRA, Caio Mário da Silva. Instituições de direito civil: contratos. $11^{\text {a }}$ edição, v. III. Rio de Janeiro: Forense, 2004.

PEREIRA, Caio Mário da Silva. Responsabilidade civil. atual. Gustavo Tepedino, 11. ed. rev. atual. Rio de Janeiro: Forense, 2016.

PERLINGIERI, Pietro. Normas constitucionais nas relações privadas. Revista da faculdade de direito da UERJ, n. 6 e 7, 1998/1999.

PERLINGIERI, Pietro. Perfis do direito civil. Rio de Janeiro: Renovar, 1999.

RIBEIRO, Alex. Caso Escola Base: Os abusos da imprensa. São Paulo: Editora Ática, 2003.

RODOTÀ, Stefano. A vida na sociedade de vigilância. Rio de Janeiro: Renovar, 2006.

RODOTÀ, Stefano. A vida na sociedade da vigilância (coord. Maria Celina Bodin de Moraes). Rio de Janeiro: Renovar, 2008.

SARLET, Ingo Wolfgang. Liberdade de expressão e biografias não autorizadas — notas sobre a ADI 4.815. Revista Eletrônica CONJUR. 19 jun. 2015. Disponível em < https://www.conjur.com.br/2015-jun-19/direitos-fundamentais-liberdade-expressaobiografias-nao-autorizadas>. Acesso em 24/06/2018.

SARMENTO, Daniel. Liberdades Comunicativas e Direito ao Esquecimento na ordem constitucional Brasileira. Parecer proferido aos Recursos Especiais $\mathrm{n}^{\circ} 1.334 .097$ ("caso Chacina da Candelária") e no 1.335.153 ("caso Aída Curi"). Rio de Janeiro, 22 jan. 2015. 
Disponível em: http://www.migalhas.com.br/arquivos/2015/2/art20150213-09.pdf. Acesso em 24/06/2018.

SCHREIBER, Anderson. Direito civil e Constituição. São Paulo: Atlas, 2013.

SCHREIBER, Anderson. Marco Civil da Internet: avanço ou retrocesso? A responsabilidade civil por dano derivado do conteúdo gerado por terceiro. In: DE LUCCA, Newton; SIMÃO FILHO; Adalberto; LIMA, Cíntia Rosa Pereira de (coords). Direito \& Internet - Tomo II: Marco Civil da internet (Lei no 12.965/2014). São Paulo: Quartier Latin, 2015a.

SCHREIBER, Anderson. Manual de Direito Civil Contemporâneo. São Paulo: Saraiva Educação, 2018.

SCHREIBER, Anderson. Novos paradigmas da responsabilidade civil: da erosão dos filtros da reparação à diluição dos danos $-6^{\text {a }}$ ed. São Paulo: Atlas, 2015 b.

SCHREIBER, Anderson; KONDER, Carlos Nelson. Uma agenda para o direito civilconstitucional. Revista Brasileira de Direito Civil, volume 10, Out /Dez 2016.

THE GUARDIAN, Facebook backs down from 'napalm girl' censorship and reinstates photo. Grã-Bretanha, 09 set. 2016. Disponível em <https://www.theguardian.com/technology/2016/sep/09/facebook-reinstates-napalm-girlphoto $>$. Acesso em 28 mar. 2018.

TEPEDINO, Gustavo. Normas Constitucionais e Direito Civil na Construção Unitária do Ordenamento. In: Temas de Direito Civil - Tomo III. Rio de Janeiro: Renovar, 2009.

TEPEDINO, Gustavo. O direito-civil constitucional e suas perspectivas atuais. In: Temas de Direito Civil - Tomo III. Rio de Janeiro: Renovar, 2009. 